F. Kees, E. Strehl, P. Dominiak, H. Grobecker, K. Seeger, G. Seidel, B. Neuhaus, L. Safrany

\title{
Cefotaxime and Desacetyl Cefotaxime in Human Bile
}

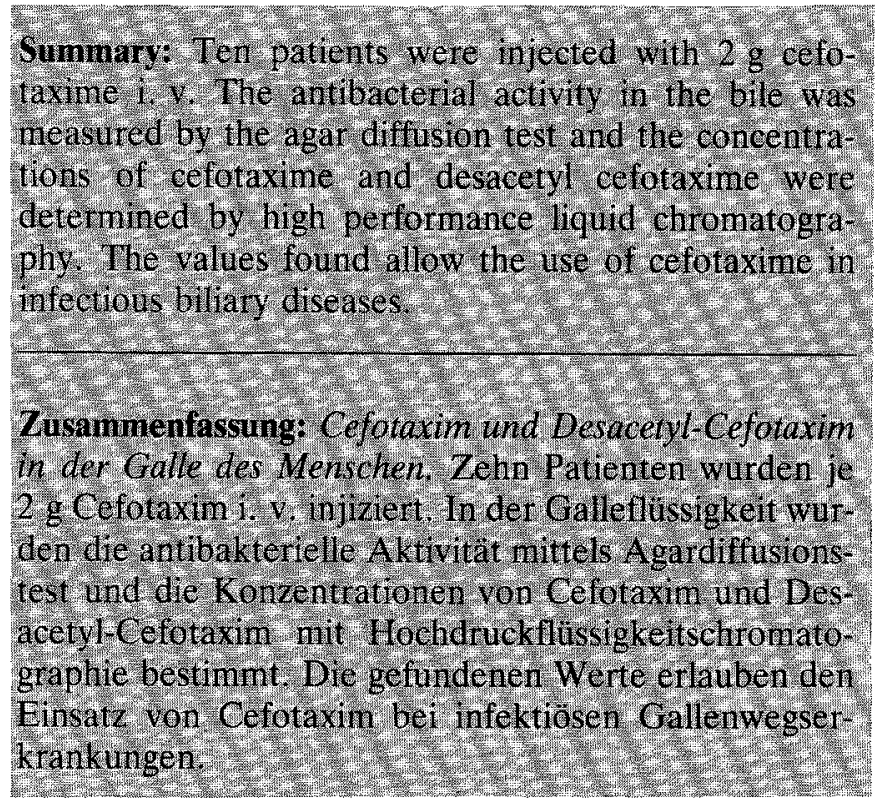

\section{Introduction}

In a previous paper we reported on the determination of cefotaxime and desacetyl cefotaxime in human and rat serum after an i.v. injection of this cephalosporin (1); the concentrations of the parent compound and its metabolite in human bile were also briefly described.

It has been shown that older cephalosporins with a 3acetoxymethyl substituent, e. g. cephalothin, are metabolised to the respective desacetyl compounds (2). The degradation of cefotaxime to desacetyl cefotaxime has also been observed in man and was simultaneously reported from other laboratories $(3,4)$.

The purpose of this paper is to report in detail on the concentrations of cefotaxime and its antimicrobially active metabolite in human bile, measured both by high performance liquid chromatography (HPLC) and by bioassay with a selective test organism after an i.v. injection of $2 \mathrm{~g}$.

\section{Patients and Methods}

Ten patients, three men and seven women aged between 32 and 82 years, were given a loading dose of $2 \mathrm{~g}$ cefotaxime administered i.v. over $3 \mathrm{~min}$. The patients were selected for the study if physical examination suggested an infection of the gall bladder. None of the patients had received any antibacterial drugs beforehand. Informed written consent was obtained from each patient.

Bile was collected through a catheter inserted into the bile duct as for ERCP and collected in nine fractions: before the injection of cefotaxime and $5,10,30,60,90,120,240$ and $360 \mathrm{~min}$ after the injection. The samples were frozen and stored at $-20^{\circ} \mathrm{C}$ until assayed.

The assay of cefotaxime and desacetyl cefotaxime by HPLC or bioassay with Escherichia coli $\mathrm{V}$ 6311/65 were described in detail in our previous paper (1).

\section{Results}

Figure 1 shows the average time-concentration curves of cefotaxime and desacetyl cefotaxime in the bile of eight patients following an i.v. injection of $2 \mathrm{~g}$. Because the test organism is slightly susceptible to desacetyl cefotaxime, the concentrations of the parent compound are overestimated by the microbiological method. $1.5 \mathrm{~h}$ after the

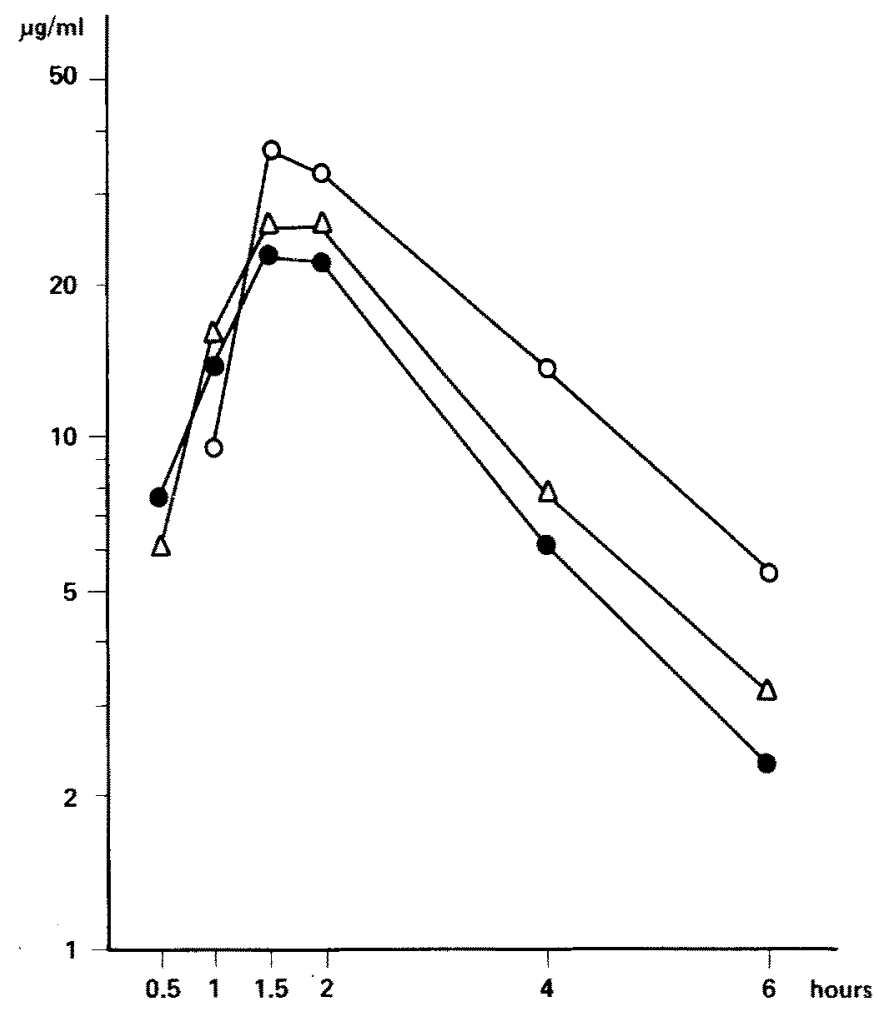

Figure 1: Concentrations of cefotaxime $(\bullet, \triangle)$ and desacetyl cefotaxime $(O)$ in human bile after an i.v. injection of $2 \mathrm{~g}$. $\longrightarrow, \mathrm{O}=$ high performance liquid chromatography; $\triangle \longrightarrow$ = bioassay.

Received: 17 March 1982/Accepted: 13 July 1982

Dr. F. Kees, Dr. E. Strehl, Dr. P. Dominiak, Prof. Dr. H. Grobecker, Lehrstuhl für Pharmakologie der Universität Regensburg, Universitätsstraße 31, D-8400 Regensburg;

Dr. K. Seeger, Prof. Dr. G. Seidel, Hoechst AG, D-6230 Frankfurt/M 80 ;

Dr. B. Neuhaus, Prof. Dr. L. Safrany, Reinhard-Nieter-Krankenhaus, Friedrich-Paffrath-Str. 100, D-2940 Wilhelmshaven. 
injection, the desacetyl cefotaxime concentration exceeded the concentration of the parent drug and remained higher during the period of investigation. Because the values found in Patients 3 and 10 differed so widely from those of the other patients, individual values of the concentrations of the parent compound and its metabolite assayed in the bile of all patients are given in Table 1.

\section{Discussion}

After an i.v. injection of $2 \mathrm{~g}$ cefotaxime, the parent compound and its microbiologically active desacetyl metabolite were demonstrated in the bile of all patients investigated. The concentrations of both cefotaxime and desacetyl cefotaxime were $2-3$ fold higher in the bile of younger patients (Patient 3, 44 years and Patient 10, 32 years) than in the eight patients aged 58-82 (Table 1). Moreover, the formation of desacetyl cefotaxime seemed to be impaired in Patient 2 (Table 1), possibly due to insufficiency of liver function (5).

The biliary concentrations of cefotaxime are about ten times lower than cefoperazone concentrations following i.v. administration (6). Nevertheless, the concentrations of cefotaxime assayed in the bile are higher than most of the minimal inhibitory concentrations tested with a variety of strains, e. g. Proteus mirabilis ATCC 14273,

Table 1: Individual concentrations of cefotaxime and desacetyl cefotaxime in the bile of ten patients following an i.v. injection of $2 \mathrm{~g}$.

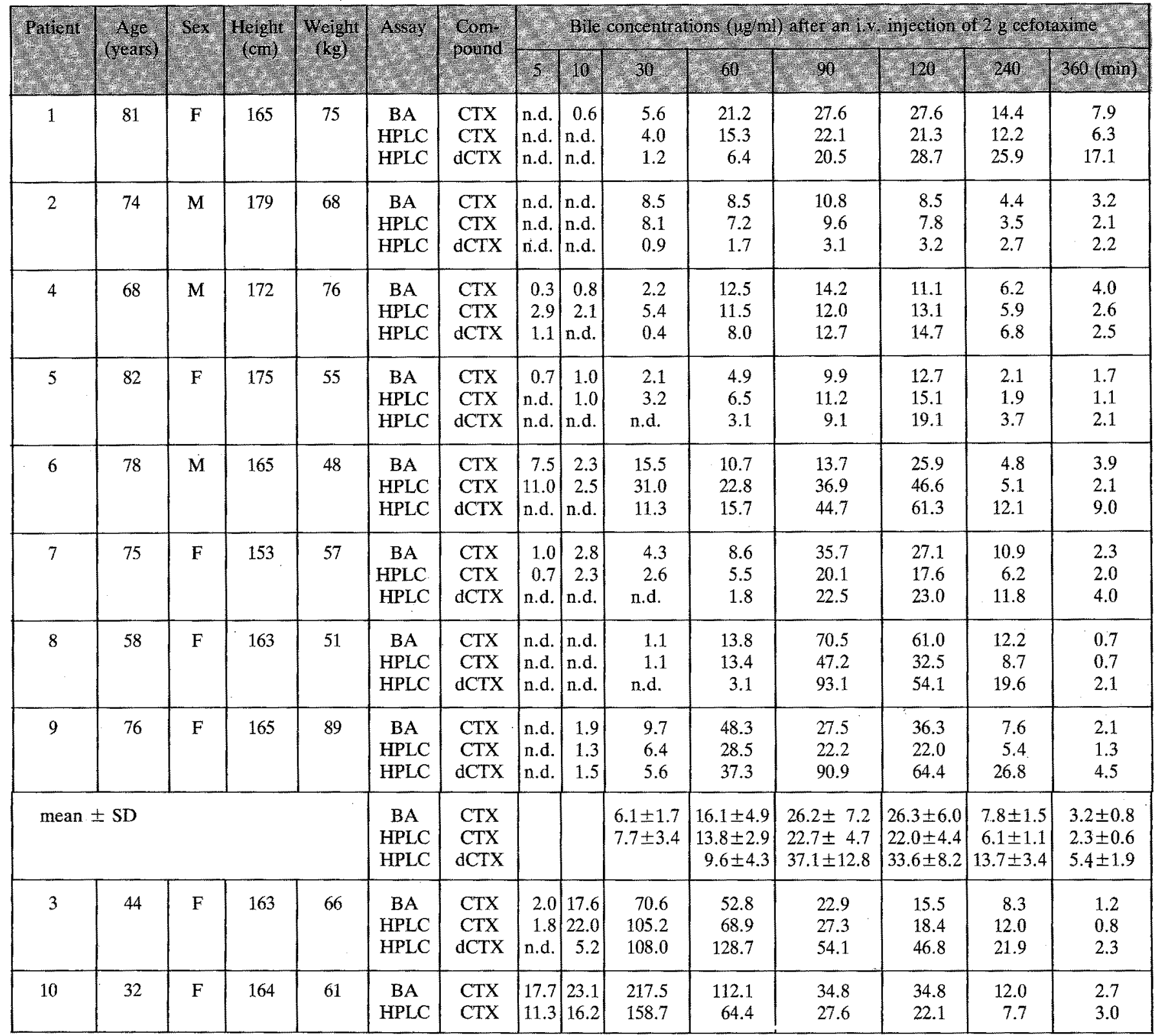

$\mathrm{BA}=$ biossay; HPLC $=$ high performance liquid chromatography; $\mathrm{n} . \mathrm{d}$. = not detected; $\mathrm{CTX}=$ cefotaxime dCTX $=$ desacetyl cefotaxime. 
Pseudomonas aeruginosa $\mathrm{K} 1118$ and E. coli $\mathrm{V} 6311 / 65$ $(1,7-9)$. On the other hand, high antibiotic concentrations in serum seem to be more important than bile levels of antibiotics in reducing the risk of infectious complications following gall bladder extirpation $(10,11)$.

Cephalosporins usually achieve high concentrations in the bile (12-16) and are generally highly effective against those organisms most commonly isolated from the biliary tract (17).

Therefore, preoperative administration of cephalosporins such as cefotaxime should reduce the risk of infectious complications during complicated cholecystectomy when anti-infective prophylaxis is indicated (18).

\section{Literature}

1. Kees, F., Strehl, E., Seeger, K., Seidel, G., Dominiak, P., Grobecker, H.: Comparative determination of cefotaxime and desacetyl cefotaxime in serum and bile by bioassay and highperformance liquid chromatography. Arzneim,-Forsch. 31 (1981) 362-365.

2. Brogard, J. M., Comte, F., Pinget, M.: Pharmacokinetics of cephalosporin antibiotics. In: Schönfeld, H., Brockmann, R. W., Hahn, F. E. (eds.): Antibiotics and Chemotherapy 25, Karger, Basel 1978, pp. 123-162.

3. Reeves, D. S., White, L. O., Holt, H. A., Bahari, D., Bywater, M. J., Bax. R. P.: Human metabolism of cefotaxime. J. Antimicrob. Chemother. 6 Suppl. A (1980) 93-101.

4. Bergan, T., Solberg, R.: Assay of cefotaxime by high-pressure liquid chromatography. Chemotherapy 27 (1981) 156-165.

5. Mashimo, K.: Penetration of antibiotics into bile. Scand. J. Infect. Dis. Suppl. 14 (1978) 172-176.
6. Shimizu, $\mathbf{K}_{\text {.: }}$ Cefoperazone: absorption, excretion, distribution and metabolism. Clin. Ther. 3 Special Issue (1980) 60-79.

7. Schrinner, E., Limbert, M., Penassel, L., Lutz, A.: Antibacterial activity of cefotaxime and other newer cephalosporins (in vitro and in vivo). J. Antimicrob. Chemother. 6 Suppl. A (1980) 25-30.

8. Wise, R., Wills, P. J., Andrews, J. M., Bredford, K. A.: Activity of cefotaxime (HR 756) desacetyl metabolite compared with those of cefotaxime and other cephalosporins. Antimicrob. Agents Chemother. 17 (1980) 84-86.

9. Strehl, E: : Therapeutische Wirkung neuer Cephalosporine: Mikrobiologische und pharmakologische Untersuchungen. Dissertation Universität Regensburg 1981.

10. Keighley, M. R. B., Drysdale, R. B., Qoraishi, A. H.: Antibiotics in biliary disease: the relative importance of antibiotic concentrations in the bile and serum. Gut 17 (1976) 495-500.

11. Pyrtek, L. J., Bartus, S. B.: An evaluation of antibiotics in biliary tract surgery. Surg. Gynecol. Obstet. 125 (1967) 101-105.

12. Trachtenberg, L., Fagelman, K. M., Polk, Jr., H. C.: The biliary tract kinetics of some cephalosporin antibiotics. Surgery 84 (1978) $342-347$.

13. Bergmann, H. D.: Cefamandole. Drug Intell. Clin. Pharm. 13 (1979) 144-149.

14. Kratochvil, P., Brandstätter, G., Adam, D., Koch, E.: Biliäre Elimination von Cefazedon. MMW 121 (1979) 497-498.

15. Müller, O., Rückert, U., Fabricius, K.: Untersuchungen zur Exkretion von Cefaclor in menschlicher Galle. Infection 7 Suppl. 6 (1979) S 624-S 627 .

16. Severn, M., Powis, S. J. A.: Biliary excretions and tissue levels of cefuroxime. A study in eleven patients undergoing cholecystectomy. J. Antimicrob. Chemother. 5 (1979) 183-188.

17. Knothe, H., Dette, G. A.: Antibiotika in der Klinik. Aesopus Verlag, Basel/München 1980, pp. 27-28.

18. Aeberhard, P.: Indikationen für prophylaktische Antibiotika in der Chirurgie. Schweiz. Rundschau Med. (PRAXIS) 70 (1981) $452-457$. 